\title{
СЛЮНКАТА КАТО АЛТЕРНАТИВНА СРЕДА ЗА ИЗСЛЕДВАНЕ НА СЕКРЕТОРЕН ИМУНОГЛОБУЛИН А (SIGA) В СЛЮНКА ПРИ ПАЦИЕНТИ В ТЕРМИНАЛЕН СТАДИЙ НА ХРОНИЧНО БЪБРЕЧНО ЗАБОЛЯВАНЕ НА ЗАМЕСТИТЕЛНО ЛЕЧЕНИЕ
}

\author{
Десислава Константинова ${ }^{1}$, Анна Ненова-Ногалчева ${ }^{2}$, Стоянка Танчева $^{3}$
}

${ }^{1}$ Катедра по протетична дентална медицна, Медицинки университет - Варна

${ }^{2}$ Катедра по орална и лицево-челюстна хирургия, Медицински университет - Варна

${ }^{3}$ Катедра по обща медицина и клинична лаборатория,

Медицински университет - Варна

\section{SALIVA AS AN ALTERNATIVE MEDIUM FOR TESTING SECRETORY IMMUNOGLOBULIN (SIGA) IN PATIENTS WITH END-STAGE CHRONIC KIDNEY DISEASE ON RENAL REPLACEMENT THERAPY}

\author{
Desislava Konstantinova ${ }^{1}$, Anna Nenova-Nogalcheva ${ }^{2}$, Stoyanka Tancheva ${ }^{3}$ \\ ${ }^{1}$ Department of Prosthetic Dentistry, Medical University - Varna, Bulgaria \\ ${ }^{2}$ Department of Oral Surgery, Medical University - Varna, Bulgaria \\ ${ }^{3}$ Department of General Medicine and Clinical Laboratory, Medical University - Varna, \\ Bulgaria
}

\section{PEЗЮME}

Цел: Целта е да се проучи възможността за изследване на SIgA в слюнка при пациенти в терминален стадий на хронично бъбречно заболяване, провеждащи хрониодиализа и здрави контроли.

Материал и методи: Изследвани са общо 104 пациенти от които 70 души (клинична група) в терминален стадий на хронично бъбречно заболяване на заместително течение със средна възраст 58,9 (SD=14,46) и контролна група от 34 души, клинично здрави тииа, без общи заболявания със средна възраст 21,76 години (SD=1,79). На всички участниии в изследването беше проведено количествено измерване на SIgA по метода на радиална имунодифузия (метод Mancini).

Резултати: Сравнителният анализ показва, че съществува значителна разлика в нивата на SIgA на пациентите от двете изследвани групи. Средните стойностите на SIg А на пациентите

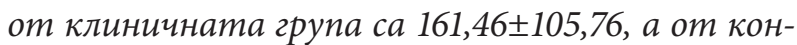

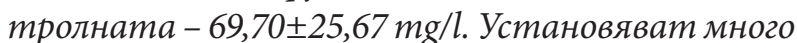
по-завишени нива на SIgA при пациентите с ХБЗ в сравнение със здравите участници.

\begin{abstract}
The authors' objective was to measure SIgA in saliva in control healthy subjects and in patients with end-stage chronic kidney disease (CKD), undergoing chronic dialysis treatment.

Material and methods. The units of observation were 104 patients: 70 patients (Clinical Group) with chronic kidney disease on hemodialysis, with a mean age of 58.9 years $(S D=14.46)$; and 34 clinically healthy subjects (Control Group), without any common diseases, with a mean age of 21.76 years $(S D=1.79)$. All participant had their SigA levels measured from a salivary liquid medium using Radial Immunodiffusion.

Results: The comparative analysis revealed substantial differences in the SigA values in patients from both study groups. SIgA mean values of the participants from the Clinical Group and the Control Group were $161.46 \pm 105.76$ and $69.70 \pm 25.67 \mathrm{mg} / \mathrm{l}$, respectively. The data indicated significantly higher SigA levels in CKD patients compared to healthy subjects.

Conclusion: Saliva is a particularly suitable medium for the study of SigA and plays a key role in oral immunity. SIgA values differed statistically in control healthy subjects and in end-stage CKD patients, undergoing chronic dialysis treatment.
\end{abstract}


Заключение: Слюнката е особено подходящза среда за изстедване на SigA, който от своя страна има ключова роля за оралния имунитет. Стойностите на SIgA се различават статистически достоверно при здрави тииа и пациенти в терминален стадий на хронично бъбречно заболяване, провеждаши хрониодиализа.

Ключови думи: ХБЗ, S IgA, хрониодиализа

\section{ВЪВЕДЕНИЕ}

Хроничното бъбречно заболяване (CKD) е световен здравен проблем с тенденция към нарастване на заболеваемостта (1). Крайният етап на хронично бъбречно заболяване се нарича терминална фаза на бъбречно заболяване. На този етап бъбреците вече не могат да функционират самостоятелно и да отделят излишните течности от тялото. Терминалният стадий на ХБЗ изисква бъбречнозаместващо лечение - перитонеална диализа, хемодиализа или бъбречна трансплантация $(2,3,4,5)$. При пациенти с бъбречна болест в крайна фаза оралното здраве също може да бъде значително засегнато. Вследствие на заболяването и диализното лечение се появяват типични орални изяви - сухота в устата, промяна на слюнчения състав и др. $(6,7,8)$. Имуноглобулин A (IgA, наричан още SIgA) е антитяло, което играе важна роля в мукозния имунитет. В слюнката се откриват SIgA антитела, които са естествени и реактивни срещу различни сапрофитни бактерии. Тези антитела могат да контролират оралната микрофлора чрез ограничаване на микробната адхезия към устната лигавица и зъбите $(9,10,11)$. Чрез индуциране на SIgA антитела може да бъде осигурен лигавичният имунитет към етиологични фактори на кариозни лезии и пародонтопатии от бактериален произход (12). В проучване, проведено във Финландия от Vesterinen и сътрудници, се изследват концентрациите на SIgA при пациенти на хрониодиализа и на пациенти след трансплантация на бъбрек. Резултатите показват, че концентрацията на SIgA са най-високи в етапа на хемодиализа, а след бъбречна трансплантация се наблюдава понижение на стойностите. Това вероятно се дължи на предписаните имуносупресори и намаляване на плазмената урея (13).

\section{ЦЕЛ}

Целта е да се проучи възможността за изследване на SIgA в слюнка при пациенти в термина-
Keywords: CKD, SIgA, chronic dialysis

лен стадий на хронично бъбречно заболяване, провеждащи хрониодиализа и здрави контроли.

\section{МАТЕРИАЛ И МЕТОДИ}

Единици на наблюдение бяха 104 пациенти, от които 70 души (клинична група) в терминален стадий на хронично бъбречно заболяване на заместително лечение (70 души, от които 32 мъже $(46.38 \%)$ и 38 жени $(53.62 \%)$ на хрониодиализно лечение със средна възраст 58.9, SD=14,46). Контролната група обхващаше пациенти без общи заболявания, във функционално физиологично равновесие на организма (34 души, от които 20 жени (59\%) и 14 мъже (41\%) със средна възраст 21,76 години, $\mathrm{SD}=1,79)$.

Изследването беше одобрено от Комисията по етика на научните изследвания при МУ-Варна с протокол №55/16.06.2016 г.

Пробите от слюнка бяха събирани от пациентите по начина на нестимулирано пасивно изтичане, без да се използват саливети, сорбети, памук и др., на гладно сутрин между 10.00 и 11.00 ч., за да се избегне дневната вариабилност в слюнчения състав. Устната кухина се изплакваше с вода 10 мин. преди събирането на материала. Количественото измерване на SIgA беше проведено по метода на радиална имунодифузия (метод Mancini) (14). Всяка имуноплака IgA (Фиг. 1) е продукт, представляващ готов агаров гел, който съдържа античовешки, моноспецифични високотитърни анти IgA антисеруми. Антитялото се включва в самия агаров гел, след това се прави ямка и се нанася антигенът, който дифундира в гела и дава преципитат във вид на окръжност. Колкото повече е антигенът, толкова е по-широка получената окръжност. Получените диаметри $(\mathrm{mm})$ се отчитат със специална милиметрова линийка.

Получените резултати бяха обработени статистически с пакета от приложни програми за анализ на данни от епидемиологични и клинични проучвания - SPSS for Windows, версия 16.00 (15.11.2007). Бяха използвани следните статис- 


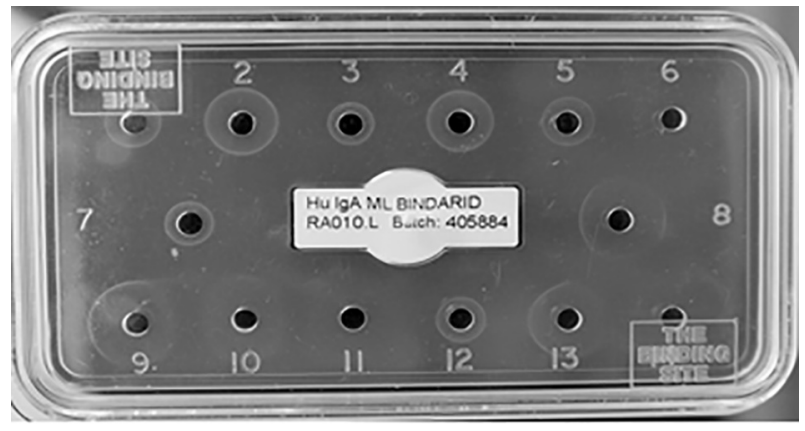

Фиг. 1. Плака $\operatorname{IgA}$

тически методи: описателна статистика за качествени данни (честотни и процентни таблици) и изходни графики; кръстосани таблици за
Графичното разпределението на стойностите на SIgA са представена на Фиг. 2 А и Б. От фигурата се вижда, че значителна част от стойностите на SIgA в клиничната група са локализирани в горната част на разпределението на квартилната диаграма.

В резултат на проведената радиална имунодифузия се установяват следните стойности на SIgA (Табл. 1):

Отнасянето на представените данни (стойности на SIgA в клиничната група $161,46 \pm 12,64059$ ) към цялата популация на пациенти, страдащи от ХБЗ в терминален стадий в България, позволява да бъде изведен 95\% до-

Таблииа 1. Честотно разпределение на изследваните параметри

\begin{tabular}{|l|c|c|}
\hline Величини & Клинична група $(\mathbf{N}=\mathbf{7 0})$ & Контролна група $(\mathbf{N}=\mathbf{3 4})$ \\
\hline Средна стойност & $161,46 \pm 12,64059$ & $69,70 \pm 5,74003$ \\
\hline Стандартно отклонение (Ст. грешка) & $105,76 \pm 8,00$ & $25,68 \pm 4,80$ \\
\hline
\end{tabular}

качествени данни; номинални корелации Phi и Cramer's V за връзка между качествени променливи; Pearson's chi-square test за връзка между качествени променливи и изходни графики.

\section{РЕЗУЛТАТИ}

Анализът на данните за разпределението на стойностите на SIgA, който беше проведен чрез теста на Kolmogorov-Smirnov показва, че в рамките на клиничната група няма нормално разпределение $(\mathrm{R}=0,148, \mathrm{p}=0,001)$, а при контролната група показва, че разпределението е близко до нормалното $(\mathrm{R}=0,138, \mathrm{p}=0,200)$. Така определените от нас стойности за нивата на SIgA в двете групи удовлетворяват изискването за достоверност на представените резултати.

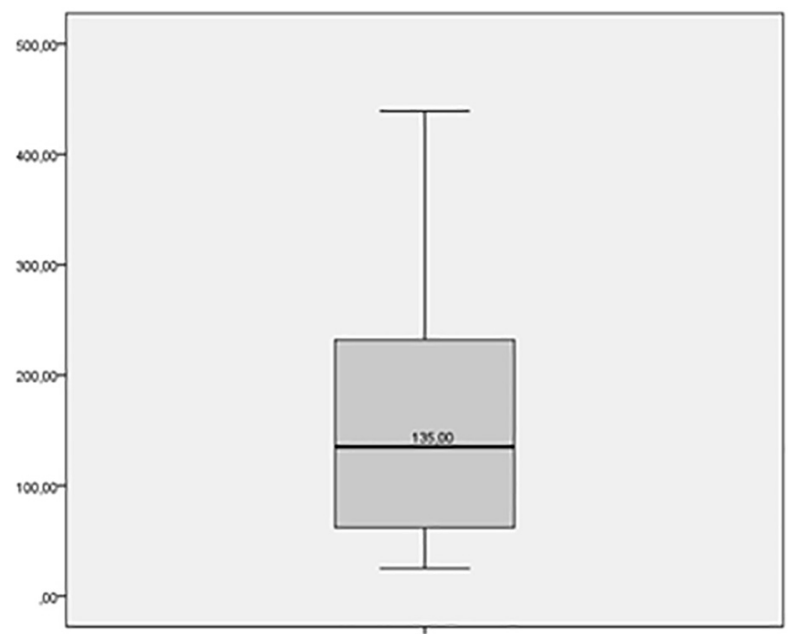

Фиг. 2 А. Графично разпределението на стойностите на SIgA в клиничната група

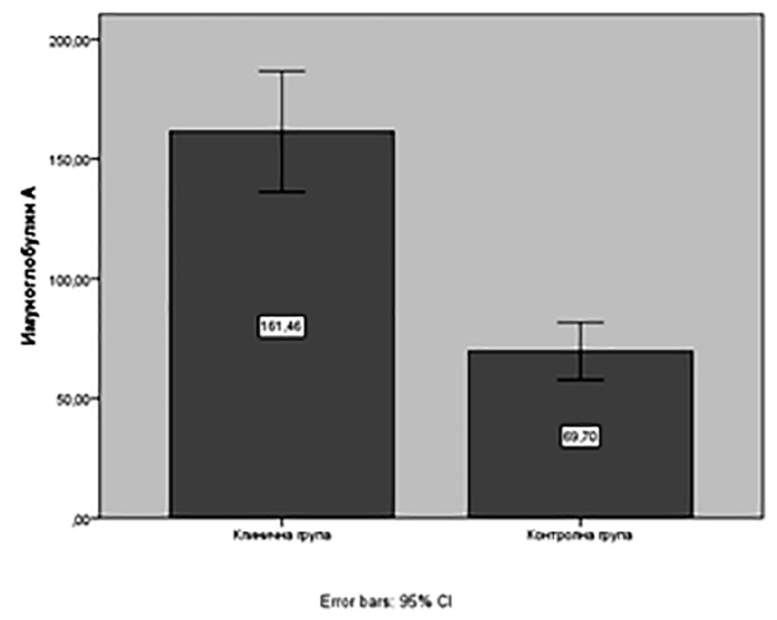

Фиг. 3. Графично представяне на данните за двете изследвани групи

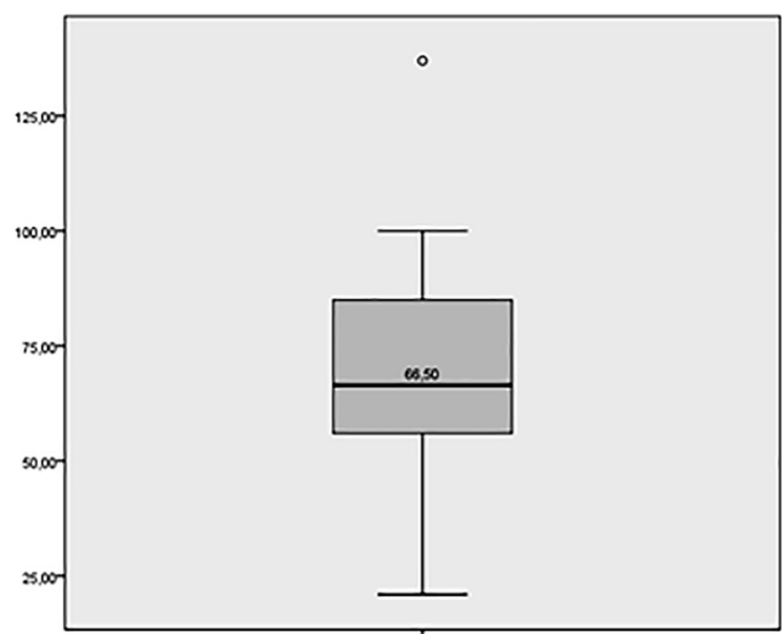

Фиг. 2 Б. Графично разпределението на стойностите на SIgA в контролната група 
верителен интервал за нивата на SIgA (най-ниски стойности - 138,32mg/l, а най-високи $186,32 \mathrm{mg} / \mathrm{l})$. За здравите пациенти (контролна група) очакваните стойности са съответно: найниска - 59,80mg/l, и най-висока - 80,65mg/l.

Сравнителният анализ показва, че съществува значителна разлика в нивата на SIgA на пациентите от двете изследвани групи (Фиг. 3).

\section{ДискУсия}

Необходими са редица допълнителни проучвания сред пациентите с ХБЗ, за да се установят факторите, обуславящи взаимовръзката между основното заболяване или последствията от диализното лечение и мукозния имунитет (15, $16,17,18)$. За целта е необходим надежден, безопасен, приемлив и лесен за изпълнение на участниците метод за събирането на проби $(17,19)$. Нашето проучване показва, че като източник на биологична течност слюнката има няколко предимства. Тя се събира неинвазивно и по-лесно в сравнение с кръв и може с голяма надеждност да се използва за измерване на важни биохимични и имунологични маркери като секреторен имуноглобулин A (SIgA). От проведеното изследване се установяват много по-завишени нива на SIgA при пациентите с ХБЗ в сравнение със здравите участници. Тези резултати потвърждават резултатите и на други изследователи (20).

\section{ЗАКЛЮЧЕНИЯ}

Слюнката е подходящ секрет за изследване на важни биологични показатели. Респондентите могат сами да отделят пробите, което значително намалява себестойността на проучването - особено когато са необходими периодични повтарящи се изследвания. Нашите резултати показват, че при болните с ХБЗ слюнката като среда е особено подходяща за изследване на SIgA, който има ключова роля за оралния имунитет. Проучването позволява определяне 95\% доверителни интервали за нивата на SIgA в клиничната и контролната група. Потвърждава се и влиянието на групата върху стойностите на SIgA.

\section{ЛИТЕРАТУРА}

1. Astor BC, Matsushita K, Gansevoort RT, Kasiske BL, Eckardt KU et al. The definition, classification and prognosis of chronic kidney disease: a KDIGO Controversies Conference report. Kidney Int 2011; 80:17-28.
2. Abboud H, Henrich WL. Clinical practice. Stage IV chronic kidney disease. N Engl J Med 2010; 362: 56- 65.

3. Tonelli M, Pannu N, Manns B. Oral phosphate binders in patients with kidney failure. N Engl J Med 2010; 362:1312-24.

4. Fogarty DG, Tall MW. A stepped are approach to the management of chronic kidney disease. In: Taal MW, Chertow GM, Marsden PA et al. (eds.). Brenner and Rector's the Kidney. 9th ed. Philadelphia,; 2011.

5. Upadhyay A, Earley A, Haynes SM, Uhlig K. Systematic review: blood pressure target in chronic kidney disease and proteinuria as an effect modifier. Ann Intern Med 2011; 154: 541-8.

6. Kho HS, Lee SW, Chung SC, Kim YK. Oral manifestations and salivary flow rate, $\mathrm{pH}$, and buffer capacity in patients with endstage renal disease undergoing hemodialysis. Oral Surg Oral Med Oral Pathol Oral Radiol Endod 1999; 88: 316-9.

7. Klassen JT, Krasko BM. The dental health status of dialysis patients. J Can Dent Assoc 2002; 68: 34- 38 .

8. Bayraktar G, Kazancioglu R, Bozfakioglu S, Yildiz A, Ark E. Evaluation of salivary parameters and dental status in adult hemodialysis patients. Clin Nephrol 2004; 62: 380-3

9. Bokor-Bratic M. Clinical significance of analysis of immunoglobulin A levels in saliva. Medicinskipregled 2000; 53: 164-8.

10. Dodds MW, Jonson DA, Yeh CK. Health benefits of saliva: a review. J Dentistry 2005; 33(3): 223-33.

11. Gonçalves TS, Morganti MA, Campos LC, Rizzatto SM, Menezes LM. Allergy to autopolymerized acrylic resin in an orthodontic patient. Am J Orthod Dentofac Orthop 2006; 129(3): 431-5.

12. Marcotte H, Lavoie MC. Oral microbial ecology and the role of salivary immunoglobulin A.Microbiol Mol Biol Rev. 1998 Mar;62(1):71-109.)

13. Vesterinen M, Ruokonen H, Furuholm J, Honkanen E, Meurman JH. Oral health in predialysis patients with emphasis on 
diabetic nephropathy. Clin Oral Investig 2011; 15: 99-104

14. Mancini GA, Carbonara AO, Heremans JF. Immunochemical quantitation of antigens by single radial immunodiffusion. Immunochemistry, 1965, 2.3: 235IN5-254IN6.

15. Gunnar MR, Bruce J, Hickman SE. Salivary cortisol response to stress in children, Adv. Psychosom. Med., 22 (2001), pp. 52-60

16. Hertzman C. The biological embedding of early experience and its effects on health in adulthood Ann. N.Y. Acad. Sci., 896 (1999), pp. $85-95$

17. Kelly S, Hertzman C, Daniels M. Searching for the biological pathways between stress and health, Ann. Rev. Public Health, 18 (1997), pp. 437-462

18. Singer BH, Ryff CD. New Horizons in Health National Academy Press, Washington DC (2001)

19. Wadsworth MEJ, Butterworth SL, Hardy RJ, Kuh DJ, Richards M. et al. ConnorThe life course prospective design: an example of benefits and problems associated with study longevitySoc. Sci. Med., 57 (2003), pp. 2193-2205

20. Hatem FA, Mohammad ZJ. Salivary IgA in chronic kidney disease patients undergoing hemodialysis in Missan governorate. Journal of Baghdad College of Dentistry, 2015, 27.2: 54-57. 